\title{
Effect of cyclosporin A on the allergen-induced late asthmatic reaction
}

Bhupinder S Sihra, Onn M Kon, Stephen R Durham, Samantha Walker, Neil C Barnes, A Barry Kay

\begin{abstract}
Background - The allergen-induced late asthmatic reaction (LAR) is associated with mucosal inflammation involving several cell types including activated $T$ lymphocytes and eosinophils. In contrast, the early asthmatic reaction (EAR) is considered to result from rapid allergeninduced release of bronchoconstrictor mediators from IgE sensitised mast cells. Cyclosporin A has efficacy in chronic severe corticosteroid-dependent asthma and is believed to act principally by inhibiting cytokine mRNA transcription in T lymphocytes. However, it has effects on other cell types in vitro, including the inhibition of exocytosis/degranulation events in mast cells. It was therefore hypothesised that cyclosporin A would attenuate both the EAR and LAR in subjects with mild asthma.
\end{abstract}

Methods - Twelve sensitised atopic asthmatic subjects with documented dual asthmatic responses were studied in a double blind, placebo controlled, crossover trial. On two separate study visits subjects received two oral doses of either cyclosporin A or matched placebo before inhaled allergen challenges. The forced expiratory volume in one second $\left(\mathrm{FEV}_{1}\right)$ was measured half hourly for eight hours and blood eosinophil counts were analysed three, six, and 24 hours after the challenge. Treatment effects on blood eosinophil counts as well as the EAR and LAR, respectively defined as the areas under the curve (AUC) of $\mathrm{FEV}_{1}$ changes from baseline between 0-1 and 4-8 hours after challenge, were compared by non-parametric crossover analysis.

Results - Cyclosporin A reduced both the LAR (median AUC - 41.9 1.h (interquartile range -82.7 to -12.4$)$ for cyclosporin $A$ and $-84.51 . h(-248.9$ to -39.1$)$ for placebo; $p=0.007)$ and the late increase in blood eosinophils (median $0.2 \times 10^{9} / 1$ (0.15 to 0.4) for cyclosporin $A$ and $0.4 \times 10^{9} l$ $1(0.25$ to 0.55$)$ for placebo; $p=0.024)$ but had no effect on the EAR. The reduction of the LAR by cyclosporin A correlated significantly with prechallenge blood concentrations of cyclosporin $A(r=0.6, p=$ 0.028).

Conclusions - These data are consistent with the concept that cyclosporin $A$ has anti-inflammatory actions in asthma resulting from inhibition of mRNA transcription of eosinophil-active cytokines, predominantly in T lymphocytes. Cyclosporin $A$, possibly in its inhaled form, or other agents which prevent cytokine gene transcription may therefore have potential in ameliorating the inflammatory component of asthma.

(Thorax 1997;52:447-452)

Keywords: cyclosporin A, eosinophils, late asthmatic reactions.

It is well recognised that bronchial allergen challenge of appropriately sensitised atopic asthmatic subjects provokes an immediate bronchoconstrictor response (usually within 30 minutes) which resolves within 1-2 hours. This is known as the early asthmatic reaction (EAR). In some asthmatic subjects this is followed by a more sustained delayed-in-time late phase asthmatic reaction (LAR) which peaks within eight hours and resolves within 24 hours (although an associated increase in bronchial hyperresponsiveness may last for several days). ${ }^{1}$

The mechanisms of EAR and LAR to inhaled allergen and the associated increase in bronchial hyperresponsiveness have been extensively studied. The EAR is believed to result primarily from the rapid release of preformed histamine and newly generated lipid mediators such as cysteinyl leukotrienes and prostanoids ${ }^{23}$ from IgE sensitised mast cells. In contrast, evidence from a number of studies suggests that the LAR may be attributable to mucosal infiltration with inflammatory cells. ${ }^{4-6}$ Particular features of this bronchial inflammatory response include $T$ lymphocyte activation, local eosinophil accumulation, and increased production of "eosinophil-active" cytokines. ${ }^{5-7}$ This is associated with increased numbers of peripheral blood eosinophils. ${ }^{89}$ The mechanism by which eosinophils are believed to contribute to the sustained LAR may be the result of the elaboration of cysteinyl leukotrienes which cause smooth muscle contraction, mucosal oedema, and mucus hypersecretion. In addition, release of basic proteins from secondary granules is believed to contribute to airway hyperresponsiveness (reviewed by Wardlaw et al. ${ }^{10}$ Thus, the LAR is generally considered to be a model of mucosal inflammation now recognised as an integral part of the asthma process even in patients with mild disease. ${ }^{11}$ The separate mechanisms suggested for the EAR and LAR are reflected in the different profiles of inhibition by pharmacological agents - for example, short acting $\beta_{2}$ agonists inhibit the EAR whereas glucocorticoids block the LAR. ${ }^{12}$ 
Table 1 Patient demographic data

\begin{tabular}{llllllll}
\hline $\begin{array}{l}\text { Subject } \\
\text { no. }\end{array}$ & Sex & $\begin{array}{l}\text { Age } \\
\text { (years) }\end{array}$ & $\begin{array}{l}\text { Weight } \\
(\mathrm{kg})\end{array}$ & $\begin{array}{l}\text { Regular } \\
\text { medication }\end{array}$ & $\begin{array}{l}\text { Baseline FEV } \\
\text { (\% predicted) }\end{array}$ & $\begin{array}{l}\text { Challenge } \\
\text { allergen }\end{array}$ & $\begin{array}{l}P_{20} \text { allergen } \\
\text { (BU/ml) }\end{array}$ \\
\hline 1 & $\mathrm{~F}$ & 45 & 55.9 & B & 108 & C & 14000 \\
2 & $\mathrm{~F}$ & 24 & 55.1 & B, IS & 92 & HDM & 1100 \\
3 & $\mathrm{~F}$ & 24 & 60.0 & B, IS & 95 & C & 12250 \\
4 & M & 39 & 70.0 & B & 90 & TGP & 2500 \\
5 & F & 28 & 52.9 & B & 113 & C & 8000 \\
6 & F & 23 & 68.0 & B, IS & 110 & HDM & 12500 \\
7 & M & 23 & 78.0 & B, NS & 107 & HDM & 2400 \\
8 & M & 25 & 89.0 & B & 92 & HDM & 1000 \\
9 & F & 26 & 59.7 & B & 105 & TGP & 2200 \\
10 & F & 24 & 95.4 & B & 95 & C & 10400 \\
11 & M & 35 & 69.3 & B, IS & 96 & C & 5000 \\
12 & M & 42 & 111.0 & B & 102 & TGP & 1000 \\
\hline
\end{tabular}

$\mathrm{B}=$ short acting $\beta$ agonist; IS = inhaled corticosteroid; NS=intranasal corticosteroid; $\mathrm{C}=\mathrm{cat}$ dander; $\mathrm{HDM}=$ house dust mite; $\mathrm{TGP}=$ timothy grass pollen; $\mathrm{FEV}_{1}=$ forced expiratory volume in one second; $\mathrm{PC}_{20}=$ concentration of allergen provoking a fall of $20 \%$ in $\mathrm{FEV}_{1}$.

Low doses of the immunosuppressive agent cyclosporin A have been found to be effective in the treatment of a number of chronic inflammatory diseases characterised by $\mathrm{T}$ lymphocyte activation ${ }^{13-16}$ and there is accumulating evidence for a role for activated $\mathrm{T}$ cells in the pathogenesis of asthma. ${ }^{17-21}$ When cyclosporin A was added to current medication in chronic severe oral glucocorticoid-dependent asthmatic subjects over a three month period there was an improvement in lung function and fewer disease exacerbations. ${ }^{22}$ In a subsequent nine month study low dose oral cyclosporin A, but not placebo, significantly reduced the requirement for oral glucocorticoids and also produced a significant improvement in morning peak expiratory flow rates. ${ }^{23}$

Despite these observations it is not clear precisely how cyclosporin A ameliorates chronic asthma since, in addition to its inhibitory effects on the release of eosinophil-active cytokines from activated T lymphocytes, ${ }^{24}{ }^{25}$ it also inhibits other cellular functions including the rapid mediator release from mast cells in vitro and basophils ex vivo. ${ }^{2627}$ In order to dissect partially the possible effects of cyclosporin $\mathrm{A}$ on the late phase inflammatory and the early phase mast cell-mediated responses in vivo we have performed a randomised, double blind, placebo controlled, crossover study of the effects of oral cyclosporin A on the allergen-induced EAR and LAR in mild atopic asthmatic subjects. We hypothesised that cyclosporin A would inhibit both the EAR (through mast cell stabilisation) and the LAR (through inhibition of cytokine mRNA transcription by a wide variety of cell types).

\section{Methods}

PATIENTS

Twelve patients with atopic asthma were recruited from the allergy clinic of the Royal Brompton Hospital, London (table 1). The patients had a clinical history of intermittent chest tightness, wheeze or shortness of breath and documented reversible airflow obstruction ( $20 \%$ change in $\mathrm{FEV}_{1}$ ) which occurred either spontaneously or with treatment in the preceding year. No subject was receiving long acting inhaled or oral $\beta$ agonists. No subject had received immunotherapy or orally administered corticosteroids during the 12 months preceding the study. Four patients were taking inhaled corticosteroids but these were discontinued seven days prior to the allergen dose-finding visit. Patients with seasonal symptoms were studied out of the pollen season. None were smokers, and any patient with a history compatible with respiratory infection in the four weeks preceding or during the study was excluded. All patients gave written informed consent and the study was approved by the ethics committee of the hospital.

STUDY DESIGN

This was a double blind, placebo controlled, crossover study. The study period involved three inhaled allergen challenges with an interval of at least two weeks between each challenge. An initial challenge determined the allergen concentration sufficient to provoke a $20 \%$ reduction in $\mathrm{FEV}_{1}$ from the prechallenge value $\left(\mathrm{PC}_{20}\right)$ within 15 minutes of allergen exposure (the EAR). Patients who developed an LAR (defined as a decrease in $\mathrm{FEV}_{1}$ of $>15 \%$ from baseline between 4-8 hours after challenge) were enrolled into the study. Patients received either two single doses of $500 \mathrm{mg}$ cyclosporin A (in capsular form) or matched placebo before the two subsequent challenges in a predetermined random order. All other medication was withheld for at least eight hours before each allergen challenge.

At the initial assessment a full explanation of the study was given, the patient's history was taken and examination performed. Patients with any known contraindications to receiving cyclosporin A were excluded. Specific exclusion criteria were a previous or current history of gastrointestinal or liver disorders that could affect absorption, distribution, metabolism or excretion of the drug, as well as renal impairment as shown by one of the following: proteinuria $(>0.3 \mathrm{~g} / 1$ by dipstick analysis), serum creatinine $>120 \mathrm{mmol} / \mathrm{l}$, or concomitant treatment with nephrotoxic drugs. Patients with evidence of impaired liver function (any increases in serum bilirubin, aspartate aminotransferase, alkaline phosphatase or $\gamma$-glutamyl transferase more than twice the laboratory upper limits of normal) were also excluded, as were patients with a history of hypertension, cardiac disease, or epilepsy.

Skin prick tests to a panel of common aeroallergens (extracts of cat dander, dog fur, house dust mite, and timothy grass pollen) were performed, and blood was taken for an eosinophil count. The allergen used for challenge was selected on the basis of a history of clinical sensitivity supported by a positive skin prick test result (weal diameter at least $3 \mathrm{~mm}$ greater than that produced by control solution). The allergens selected for each subject are shown in table 1 .

Allergen sensitivity was determined by skin prick tests with doubling serial dilutions of allergen, starting with 20000 biological units (BU) $/ \mathrm{ml}$ house dust mite (Dermatophagoides pteronyssinus), timothy grass extracts (Phleum pratense), or cat dander (ALK, Horsholm, Den- 
mark). After challenge with inhaled saline to determine the baseline (pre-allergen) $\mathrm{FEV}_{1}$, the dose-finding allergen challenge was performed, starting with a twofold dilution below that which produced a $3 \mathrm{~mm}$ diameter skin prick weal (threshold dose for a response). Increasing twofold concentration increments (with at least 15 minutes between challenges) were given until a $20 \%$ decrease in $\mathrm{FEV}_{1}$ was achieved. Patients inhaled saline or allergen solution delivered by a Wright nebuliser (calibrated to give an output of $0.13 \mathrm{ml} / \mathrm{min}$ ) by tidal breathing for two minutes. $\mathrm{FEV}_{1}$ was recorded before challenge, every five minutes after allergen challenge for the first 30 minutes, and then half hourly for the next eight hours. At some time during the period $4-8$ hours after the challenge patients were required to demonstrate a decrease in $\mathrm{FEV}_{1}$ of at least $15 \%$ of the baseline value.

After a period of at least two weeks the patient received the first dose of study medication (either $500 \mathrm{mg}$ cyclosporin A or placebo) at 20.00 hours on the evening before allergen challenge. At 08.00 hours the following day venous blood samples were taken for cyclosporin A concentrations and eosinophil counts before the patient received the second dose of the same study medication. At 10.45 hours, after further blood samples had been taken, a saline challenge was performed to determine the baseline $\mathrm{FEV}_{1}$ (defined as the lowest $\mathrm{FEV}_{1}$ value achieved within 15 minutes following saline challenge). The allergen challenge was performed at 11.00 hours using a predetermined dose of antigen (the $\mathrm{PC}_{20}$ allergen determined at the first visit). The $\mathrm{FEV}_{1}$ was then recorded every five minutes for $30 \mathrm{~min}$ utes, then every 30 minutes for eight hours. Blood samples for further measurements of peripheral blood eosinophils were taken three, six, and 24 hours after allergen challenge and for measurement of cyclosporin A concentrations at 24 hours. The entire procedure

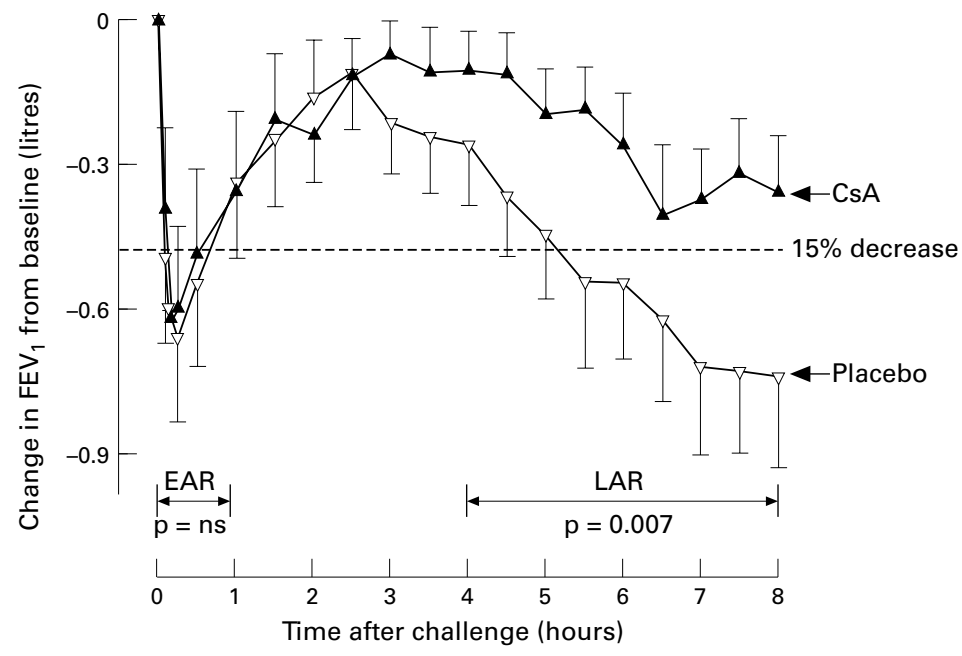

Figure 1 Effects of cyclosporin $A(C s A)$ and placebo on mean (SE) changes in forced expiratory volume in one second (FEV ) from baseline (prechallenge) values. The mean prechallenge $F E V_{1}$ values were $3.45 \mathrm{l}$ for cyclosporin $A$ and $3.44 \mathrm{l}$ for placebo. The $p$ values for individual comparisons of the effects of the two treatments on the areas under curve of changes in FEV $V_{1}$ over the 0-1 hour and 4-8 hour periods are shown. was repeated after an interval of at least two weeks, with patients receiving the alternative treatment to that received on their first treatment visit.

DATA ANALYSIS

The primary outcome measures were the magnitudes of the early (EAR) and late (LAR) asthmatic responses, defined as the area under curve (AUC) of changes in $\mathrm{FEV}_{1}$ from the baseline (or prechallenge) value during the periods $0-1$ hours and 4-8 hours after the challenge, respectively. The AUC values were calculated by the trapezoid method. Differences between the AUC values after cyclosporin $\mathrm{A}$ and placebo treatments were compared by paired analyses using a non-parametric method for crossover trials in which three separate Wilcoxon signed rank tests were performed to analyse the treatment and period effects as well as the treatment-period interaction. ${ }^{28}$ This method was also used to compare absolute blood eosinophil counts at each time point. Correlation coefficients were calculated by Spearman's method with correction for tied values. Data analysis was performed by an independent blinded statistician.

\section{Results}

Every subject complied with the treatment, achieving blood cyclosporin concentrations of more than $100 \mathrm{mg} / 112$ hours after the first dose of cyclosporin. Peak levels just before allergen challenge were more than $250 \mathrm{mg} / 1$ (mean (SE) $820(130) \mathrm{mg} / \mathrm{l})$. Nine of the 12 subjects reported some side effects (nausea or paraesthesia) after taking cyclosporin A while only one reported side effects after placebo treatment. All side effects were transient, lasting less than six hours, and were self-limiting.

$\mathrm{FEV}_{1}$

$\mathrm{FEV}_{1}$ measurements at each time point were found to be distributed normally but the AUC values for changes in $\mathrm{FEV}_{1}$ from baseline were not. Comparison by a $t$ test showed that baseline (pre-allergen) $\mathrm{FEV}_{1}$ values during each treatment arm were not significantly different (mean (SE) $3.45(0.15) 1$ for cyclosporin A, $3.44(0.16) 1$ for placebo; $\mathrm{p}=0.69)$.

The effects of cyclosporin $\mathrm{A}$ and placebo on changes in $\mathrm{FEV}_{1}$ from baseline values after allergen challenge are shown in fig 1 . There was no significant difference $(p=0.63)$ between the effects of cyclosporin $A$ and placebo on the individual AUCs during the EAR period (0-1 hour after challenge). The median (and interquartile ranges (IQR)) of AUC values during this period were $-12.0(-36.9$ to -7.0$)$ litre hours (1.h) and -17.9 ( -32.9 to -12.3$)$ 1.h after cyclosporin A and placebo, respectively. However, compared with placebo, cyclosporin A significantly reduced $(\mathrm{p}=0.007)$ the AUC values during the 4-8 hour LAR period. The median AUCs were -41.9 (IQR -82.7 to -12.4) 1.h for cyclosporin $A$ and -84.5 (IQR -248.9 to -39.1 ) 1.h for placebo. Compared 


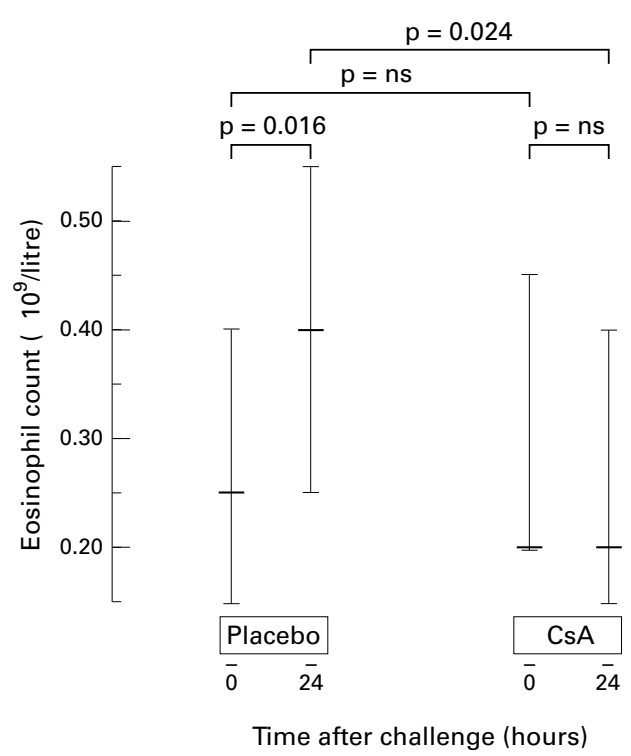

Figure 2 Effect of cyclosporin $A(C s A)$ and placebo on the LAR associated increase in blood eosinophil counts 24 hours after allergen challenge (medians and interquartile ranges shown).

with placebo, cyclosporin A treatment was associated with a median reduction in the magnitude of the LAR of $65.9 \%$ (IQR 24.1 to $79.1 \%$ ). There was a significant correlation between the percentage reduction in the magnitude of the LAR by cyclosporin A compared with placebo and blood cyclosporin A concentrations measured just prior to the allergen challenge $(r=0.6, \mathrm{p}=0.028)$.

EOSINOPHIL COUNTS

The baseline (prechallenge) absolute eosinophil counts were not significantly different for either treatment (median values 0.2 (IQR 0.2 to 0.45$) \times 10^{9} / 1$ for cyclosporin $\mathrm{A}$ and 0.25 (IQR 0.15 to 0.40$) \times 10^{9} / 1$ for placebo, $\mathrm{p}=$ 0.56). By three hours after challenge there were small but significant reductions in blood eosinophil counts from baseline values with both treatment arms (median for cyclosporin A 0.15 (IQR 0.1 to 0.35 ) $\times 10^{9} / 1, \mathrm{p}=0.016$; median for placebo 0.2 (IQR 0.1 to 0.30$) \times 10^{9} \%$ $1, p=0.023$ ) but there were no significant differences between the two treatments $(p=$ 0.94 ). Similar reductions were observed at six hours (median eosinophil count for cyclosporin A 0.15 (IQR 0.1 to 0.35$) \times 10^{9} / 1, \mathrm{p}=0.031$ for changes from baseline; median for placebo 0.1 (IQR 0.1 to 0.30$) \times 10^{9} / 1, \mathrm{p}=0.008$ ) and again there was no significant difference between treatments $(p=0.52)$. By 24 hours after allergen challenge, however, the eosinophil counts were not significantly different from baseline during treatment with cyclosporin A (median $0.2 \times 10^{9} / 1$, IQR 0.15 to $0.4, \mathrm{p}=0.80$ ) but were significantly increased during the placebo arm (median $0.4 \times 10^{9} / 1$, IQR 0.25 to $0.55, \mathrm{p}=$ $0.016)$. There was a significant difference $(\mathrm{p}=$ 0.024 ) between the effects of the two treatments on eosinophil counts at 24 hours after challenge (fig 2).
There were no significant period effects or treatment-period interactions for either the eosinophil counts or AUC of changes in $\mathrm{FEV}_{1}$.

\section{Discussion}

In this placebo controlled, double blind study we have shown that cyclosporin A modulated the late, but not the early, bronchoconstrictor reaction to inhaled allergen challenge of sensitised atopic asthmatic subjects. Furthermore, there was a significant correlation between the magnitude of the reduction of the LAR by cyclosporin A and the blood concentrations of cyclosporin A before the challenge. Cyclosporin A also abolished the increase in circulating eosinophils associated with the LAR 24 hours after allergen challenge but did not have any effect on early changes in blood eosinophil counts. Interestingly, the degree of inhibition of the LAR was similar to that observed with inhaled beclamethasone and sodium cromoglycate, drugs whose efficacy in the prophylaxis of asthma is well established. ${ }^{12}$ The dose of cyclosporin A received by the patients as a single event was higher than that used for prolonged treatment in our previous studies on chronic asthma but was similar (on a $\mathrm{mg} / \mathrm{kg}$ basis) to that given during induction of immunosuppressive therapy before organ transplantation. The objective was to ensure that a satisfactory blood concentration of cyclosporin A was rapidly achieved and then maintained during the period of maximal inflammatory activity following allergen challenge. This objective was accomplished in each patient.

The EAR is generally believed to result from bronchial smooth muscle contraction, vascular leakage, and mucosal oedema subsequent to the rapid release of pharmacological mediators such as histamine, leukotrienes $\mathrm{C}_{4}, \mathrm{D}_{4}$ and $\mathrm{E}_{4}$, and prostaglandin $\mathrm{D}_{2}\left(\mathrm{PGD}_{2}\right)$ from $\operatorname{IgE}$ sensitised mast cells. ${ }^{23}$ In contrast, the LAR is thought to be a reflection of bronchial mucosal inflammation. ${ }^{14}$ Major cellular changes in the airways associated with the allergen induced LAR include increased numbers of activated CD $4+$ T lymphocytes and eosinophils. ${ }^{6}$ The mechanism of eosinophil recruitment is complex but appears to involve the elaboration of CC chemokines (RANTES, MCP-3, MCP-4 and eotaxin) as well as the "eosinophil-active" cytokines interleukin (IL)-3, IL-5, and granulocyte/macrophage-colony stimulating factor (GM-CSF). ${ }^{29} 30$ These cytokines promote eosinophil differentiation and maturation, enhance eosinophil adhesion and locomotion, and prolong eosinophil survival. ${ }^{10}$ In particular, IL-5 is unique in its ability to differentiate the committed eosinophil precursor terminally. It also has hormone-like effects since in the guinea pig intravenous injection of IL-5 released mature eosinophils from the bone marrow. ${ }^{31}$ Potential sources of eosinophil-active cytokines include $\mathrm{T}$ lymphocytes, mast cells, eosinophils, fibroblasts, endothelial and epithelial cells. ${ }^{202132-36}$ There is considerable circumstantial evidence that eosinophil-derived products are directly involved in the patho- 
genesis of the LAR - for example, the magnitude of the allergen-induced LAR correlates closely with the numbers of activated eosinophils in bronchoalveolar lavage samples. ${ }^{6}$

Our observations of early reductions (within six hours of bronchial allergen challenge) of peripheral blood eosinophil counts are in line with previous studies ${ }^{8937}$ and may reflect early recruitment of eosinophils to the bronchial mucosa $^{3839}$ as a result of the rapid release of mast cell derived cytokines and eosinophil chemoattractants such as TNF- $\alpha$ (which promotes transendothelial migration of eosinophils), leukotriene $\mathrm{B}_{4}$, and platelet activating factor (PAF). ${ }^{32}$ The possibility that this phenomenon reflected normal circadian variation was eliminated in a separate experiment (data not shown) in which no significant variations in circulating eosinophil numbers in these subjects were observed after bronchial challenge performed at the same time of day with saline alone. The eosinophils recruited to the airways are probably involved in the initiation of the changes associated with the LAR. The observation that cyclosporin A did not appear to affect this early recruitment of circulating eosinophils may help explain why it did not completely abolish the LAR. The late increase in blood eosinophil counts 24 hours after allergen inhalation mirrors that seen in the bronchi and may reflect increased cytokine driven differentiation of eosinophils in the bone marrow and subsequent release of mature eosinophils into the circulation.

Cyclosporin A has several anti-inflammatory effects which might be relevant to the observed attenuation of the allergen-induced LAR. Its actions were originally believed to be confined to $\mathrm{CD} 4+\mathrm{T}$ lymphocytes where it inhibits allergen-induced cell activation and the transcription and translation of messenger RNA (mRNA) for several cytokines including IL-5 and GM-CSF. ${ }^{242540}$ It is now clear that it also affects cytokine production by other cell types including eosinophils, mast cells, and monocytes. $^{41-44}$ Cyclosporin A also modulates the rapid release of preformed and de novo synthesised mediators from human mast cells in vitro $^{26}$ and basophils ex vivo. ${ }^{27}$

Despite this wide array of biological activities in vitro or ex vivo it was notable that, whereas treatment with cyclosporin A modulated the LAR and the associated late increase in the peripheral blood eosinophil count in the present study, it had no effect on events believed to be associated with IgE mediated mast cell degranulation - that is, the EAR and the early reduction in circulating eosinophil numbers. The reasons for this are unclear. The pronounced effects on the LAR and the relationship between blood cyclosporin A levels and the magnitude of this reduction suggest that there was good bioavailability of the drug in the bronchial mucosa. Moreover, since the in vitro or ex vivo modulation of mast cell and basophil degranulation by cyclosporin A occurs within a matter of minutes after exposure to the drug, ${ }^{2627}$ the failure of cyclosporin A to inhibit the EAR is unlikely to reflect a latent period before the drug became effective.
The explanation most consistent with all of these observations is that, in this in vivo model, cyclosporin A exerted its anti-asthmatic effects mainly through inhibition of transcription and translation of cytokines in T lymphocytes, and possibly other cell types, rather than by significantly inhibiting release of mediators from mast cells. In this sense cyclosporin A can be considered to have anti-inflammatory as well as immunosuppressant properties. Taken together with the results of previous studies ${ }^{2223}$ these observations provide further indirect support for the involvement of eosinophil-active cytokines, of which allergen-specific $\mathrm{T}$ lymphocytes are believed to be important sources, in the pathogenesis of inflammation across the whole spectrum of asthma severity - from patients with mild asthma (such as those participating in the present study) to those with severe corticosteroid-dependent asthma. Although the use of oral cyclosporin A in mild asthma is unjustified because of its poor risk: benefit ratio, these observations suggest that safer agents which inhibit cytokine gene transcription might prove to be effective treatments for asthma without the potential side effects associated with the use of corticosteroids. An inhaled form of cyclosporin A offering the optimal combination of good local bioavailability and fewer systemic effects may be one such agent, particularly as the anti-inflammatory effects of cyclosporin A appeared to be dose related in this study. Indeed, inhaled cyclosporin A has already been shown to inhibit the LAR in an animal model. ${ }^{45}$ Such novel therapeutic agents may hold exciting prospects for the future management of asthma.

The authors would like to thank ALK, Denmark for their generous gift of allergen extracts, Drs B Assoufi and M Humbert for helping with patient recruitment, Drs C Corrigan and D Robinson for their critical appraisal of this manuscript, and Robinson for their critical appraisal of this manuscript, and
Mrs J Turner for help with statistical analysis. This work was supported by Sandoz Pharma Ltd, Basle, Switzerland.

1 Durham SR. Late asthmatic responses. Respir Med 1990; 84:263-8.

2 Casale TB, Wood D, Richerson HB, Zehr B, Zavala D, Hunninghake GW. Direct evidence of a role for mast cells in the pathogenesis of antigen-induced bronin the pathogenesis of antigen-induced

3 Liu MC, Hubbard WC, Proud D, Stealey BA, Galli SJ, Kagey-Sobotka A, et al. Immediate and late inflammatory responses to ragweed antigen challenge of the peripheral responses to ragweed antigen challenge of the peripheral
airways in allergic asthmatics. Cellular, mediator, and permeability changes. Am Rev Respir Dis 1991;144:51-8.

4 Metzger WJ, Zavala D, Richerson HB, Moseley P, Iwamoto $\mathrm{P}$, Monick M, et al. Local allergen challenge and bronchoalveolar lavage of allergic asthmatic lungs: description of the model and local airway inflammation. Am Rev Respir Dis 1987;135:433-40.

5 Bentley AM, Meng Q, Robinson DS, Hamid Q, Kay AB, Durham SR. Increases in activated T lymphocytes, eosinophils and cytokine mRNA expression for interleukin5 and granulocyte/macrophage colony-stimulating factor in bronchial biopsies after allergen inhalation challenge in atopic asthmatics. Am 7 Respir Cell Mol Biol 1993;8:35-42. 6 Robinson DS, Hamid Q, Bentley A, Ying S, Kay AB, Durham SR. Activation of CD4 + T cells, increased T Durham SR. Activation of CD $4+\mathrm{T}$ cells, increased $\mathrm{T}_{\mathrm{H}} 2-$ type cytokine mRNA expression, and eosinophil recruitment in bronchoalveolar lavage after allergen inhalation challenge in patients with atopic asthma. F Allergy Clin Immunol 1993;92:313-24.

7 Virchow JC, Walker C, Hafner D, Kortsik C, Werner P, Matthys $\mathrm{H}$, et al. T cells and cytokines in bronchoalveolar lavage fluid after segmental allergen provocation in atopi asthma. Am f Respir Crit Care Med 1995;151:960-8.

8 Dahl R, Venge P, Olsson I. Variations of blood eosinophils and eosinophil cationic protein in serum in patients with bronchial asthma: studies during inhalation challenge test. Allergy 1978;33:211-5

9 Durham SR, Loegering DA, Dunnette S, Gleich GJ, Kay AB. Blood eosinophils and eosinophil-derived proteins in allergic asthma. F Allergy Clin Immunol 1989;84:931-6. 
10 Wardlaw AJ, Moqbel R, Kay AB. Eosinophils: biology and role in disease. Adv Immunol 1995;60:151-266.

11 Laitinen LA, Laitinen A, Haahtela T. Airway mucosal inflammation even in patients with newly diagnosed asthma. Am Rev Respir Dis 1993;147:697-704.

12 Cockcroft DW, Murdock KY. Comparative effects of inhaled salbutamol, sodium cromoglycate, and beclomethasone diproprionate on allergen-induced early asthmatic responses, late asthmatic responses, and increased bronchial sponses, late asthmatic responses, and increased bronchial 79:734-40.

13 Brynskov J, Freund L, Rasmussen SN, Lauritsen K, Shaffalitzky de Muckadell O, Williams N, et al. A placebocontrolled, double-blind, randomised trial of cyclosporine controlled, double-blind, randomised trial of cyclosporine
therapy in active chronic Crohn's disease. $N$ Engl $\mathcal{F}$ Med therapy in active chic

14 Ellis CN, Fradin MS, Messana JM, Brown MD, Siegel MT, Hartley AH, et al. Cyclosporine for plaque-type psoriasis. Results of a multidose, double-blind trial. N Engl $7 \mathrm{Med}$ 1991;324:277-84.

15 Tugwell P, Bombardier C, Gent M, Bennett KJ, Bensen WG, Carette S, et al. Low dose cyclosporin in patients with rheumatoid arthritis. Lancet 1990;335:1051-4.

16 Sowden JM, Berth-Jones J, Ross JS, Motley RJ, Marks R, Finlay AY, et al. Double-blind, controlled, cross-over study of cyclosporin in adults with severe refractory atopic derof cyclosporin in adults with severe

17 Azzawi M, Bradley B, Jeffery PK, Frew A, Wardlaw AJ, Knowles $\mathrm{G}$, et al. Identification of activated T lymphocytes and eosinophils in bronchial biopsies in stable atopic asthma. Am Rev Respir Dis 1990;142:1407-13.

18 Corrigan CJ, Kay AB. CD4 T-lymphocyte activation in acute severe asthma: relationship to disease severity and atopic status. Am Rev Respir Dis 1990;141:970-7.

19 Walker C, Kaegi MK, Braun P, Blaser K. Activated T cells and eosinophilia in bronchoalveolar lavages from subjects with asthma correlated with disease severity. 7 Allergy Clin Immunol 1991;88:935-42.

20 Robinson DS, Hamid Q, Ying S, Tsicopolous A, Barkans $\mathrm{J}$, Bentley AM, et al. Predominant $\mathrm{T}_{\mathrm{H}} 2$-like bronchoalveolar T-lymphocyte population in atopic asthma. $N$ Engl f Med 1992;326:298-304.

21 Ying S, Durham SR, Corrigan CJ, Hamid Q, Kay AB. Phenotype of cells expressing mRNA for $\mathrm{T}_{\mathrm{H}} 2$-type (interleukin 4 and interleukin 5) and $\mathrm{T}_{\mathrm{H}} 2$-type (interleukin 2 and interferon $\mathrm{g}$ ) cytokines in bronchoalveolar lavage and bronchial biopsies from atopic asthmatic and normal subjects. Am f Respir Cell Mol Biol 1995;12:477-87.

22 Alexander AG, Barnes NC, Kay AB. Trial of cyclosporin in corticosteroid-dependent chronic severe asthma. Lancet 1992;339:324-8.

23 Lock SH, Kay AB, Barnes NC. Double-blind, placebocontrolled study of cyclosporin A as a corticosteroidsparing agent in corticosteroid-depend

24 Mori A, Suko M, Nishizaji Y Yamamoto $\mathrm{K}$, et al. IL 5 production by CD4 + T cells of Yamamoto K, et al. IL-5 production by CD4 + T ce suppressed by glucocorticoids and the immunosuppressants FK506 and cyclosporin A. Int Immunol 1995;7:449-57.

25 Sano T, Nakamura Y, Matsunanga Y, Takahashi T, Azuma M, Okano Y, et al. FK506 and cyclosporin A inhibit granulocyte-macrophage colony-stimulating factor production by mononuclear cells in asthma. Eur Respir $\mathcal{F}$ 1995;8:1473-8.

26 Triggiani M, Cirillo R, Lichtenstein LM, Marone G. Inhibition of histamine and prostaglandin $\mathrm{D}_{2}$ release from human lung mast cells by ciclosporin A. Int Arch Allergy Appl Immunol 1989;88:253-5.
27 Casolaro C, Spadaro G, Patella V, Marone G. In vivo characterisation of the anti-inflammatory effect of cyclosporin A on human basophils. F Immunol 1993;151:556373.

28 Pocock SJ. Cross-over trials. In: Pocock SJ, ed. Clinical trials: a practical approach. Chichester: John Wiley, 1983 116-7.

29 Ohnishi T, Kita H, Weiler D, Sur S, Sedgwick JB, Calhoun WJ, et al. IL-5 is the predominant eosinophil-active
cytokine in the antigen-induced pulmonary late-phase reaction. Am Rev Respir Dis 1993;147:901-7.

30 Woolley KL, Adelroth M, Woolley MJ, Ellis R, Jordana M, O'Byrne PM. Effects of allergen challenge on eosinophils, eosinophil cationic protein, and granulocyte-macrophage colony-stimulating factor in mild asthma. Am 7 Respir Crit Care Med 1995;151:1915-24.

31 Collins PD, Marleau S, Griffiths-Johnson DA, Jose PJ, Williams TJ. Cooperation between interleukin 5 and the chemokine eotaxin to induce eosinophil accumulation in vivo. F Exp Med 1995;182:1169-74.

32 Bradding P. Human mast cell cytokines. Clin Exp Allergy 1996;26:13-9.

33 Moqbel R, Levi-Schaffer F, Kay AB. Cytokine generation by eosinophils. F Allergy Clin Immunol 1994;94:1183-8.

34 Vancheri C, Gauldie J, Bienenstock J, Cox G, Scicchitano $\mathrm{R}$, Stanisz A, et al. Human lung fibroblast-derived granulocyte-macrophage colony stimulating factor (GM-CSF)
mediates eosinophil survival in vitro. Am 7 Respir Cell Mol Biol 1989;1:289-95.

35 Her E, Frazer J, Austen KF, Owen WF. Eosinophil haematopoietins antagonize the programmed cell death of eosinophils. Cytokine and glucocorticoid effects on eosinophils maintained by endothelial cell conditioned medium. I Clin Invest 1991;88:1982-7.

36 Abdelaziz MM, Devalia JL, Khair OA, Calderon M, Sapsford RJ, Davies RJ. The effect of conditioned medium from cultured human bronchial epithelial cells on eosinophil and neutrophil chemotaxis and adherence in vitro. Am f Respir Cell Mol Biol 1995;13:728-37.

37 Cookson WOCM, Craddock CF, Benson MK, Durham SR. Falls in peripheral eosinophil counts parallel the late asthmatic response. Am Rev Respir Dis 1989;139:458-62.

38 Aalbers R, de Monchy JGR, Kauffman HF, Smith M, Hoekstra Y, Vrugt B, et al. Dynamics of eosinophil infiltration in the bronchial mucosa before and after the late asthmatic reaction. Eur Respir $\mathcal{F}$ 1993;6:840-7.

39 Rossi GA, Crimi E, Lantero S, Gianiorio P, Oddera S Crimi P, et al. Late-phase asthmatic reaction to inhaled Crimi $\mathrm{P}$, et al. Late-phase asthmatic reaction to inhaled
allergen is associated with early recruitment of eosinophils in the airways. Am Rev Respir Dis 1991;144:379-83.

40 Siekerka JJ, Sigal NH. FK-506 and cyclosporin A: immunosuppressive mechanism of action and beyond. Curr Opin Immunol 1992;4:548-52.

41 Kita H, Ohnishi T, Okubo Y, Weiler D, Abrams JS, Gleich GJ. Granulocyte/macrophage colony-stimulating factor and interleukin-3 release from peripheral blood eosinophils and neutrophils. F Exp Med 1991;174:745-8.

42 Hatfield SM, Roehm NW. Cyclosporine and FK506 in hibition of murine mast cell cytokine production. F Pharm Exp Ther 1992;260:680-8.

43 Bonham CA, Thomson AW. Immunosuppressants (drug and monoclonal antibodies). In: Kay AB, ed. Allergy and allergic diseases. Oxford: Blackwell Science, 1997 (in press).

44 Andersson J, Nagy S, Groth CG, Andersson U. Effects of FK506 and cyclosporin A on cytokine production in vitro at a single cell level. Immunology 1992;75:136-42.

45 Arima M, Yukawa T, Terashi Y, Makino S. Effects of inhaled cyclosporin A on the allergen-induced late asthmatic response and increase in airway hyperresponsiveness in guinea pig model of asthma. Fapan f Allergol 1994;43: 1316-25. 